\title{
Variação linguística e leitura: fenômenos variáveis da fala na leitura em voz alta
}

\author{
Linguistic variation and reading: variable phenomena of speech in reading aloud
}

\author{
Alessandra Pereira Gomes Machado* \\ Universidade Federal de Sergipe \\ São Cristóvão, Sergipe, Brasil
}

Resumo: Estabelecendo um contraponto à análise da precisão na decodificação da palavra escrita na avaliação da fluência em leitura oral baseada no certo e errado (RASINSKI, 2004), este estudo funda-se na Sociolinguística Educacional (BORTONI-RICARDO, 2004) que propõe o tratamento do "erro" considerando as variantes e estilos da língua a partir de três contínuos: urbanização, oralidade-letramento e monitoração estilística. Esses contínuos compreendem a heterogeneidade da língua e a avaliação social desta, possibilitando identificar traços descontínuos, fenômenos que recebem maior estigma social, e traços graduais, presentes na oralidade de quase todos os brasileiros. Este estudo objetiva analisar os fenômenos variáveis transpostos para a leitura em voz alta de estudantes do $6^{\circ}$ ano do ensino fundamental de duas escolas públicas de Sergipe e verificar qual a rota de leitura esses estudantes estão acessando que podem nos dar pistas da proficiência em leitura. A sessão de gravação foi realizada, no ano letivo de 2016, com 74 estudantes, com idade entre 10 e 14 anos. A análise foi realizada em 1 minuto da leitura em voz alta de 2 textos adequados ao currículo do leitor (DENO, 2003), totalizando um corpus de 148 minutos de áudio. Os resultados mostram que foi possível verificar os fenômenos variáveis na leitura em voz alta e que eles podem nos dar pistas das rotas de leitura, possibilitando identificar os possíveis leitores proficientes e não taxar como "erro" o apagamento de R na desinência verbal de infinitivo ou de $\mathrm{S}$ no núcleo de $\mathrm{SN}$ na posição mais à direita ou ainda na monotongação de /ow/ numa avaliação de leitura.

Palavras-chave: Avaliação de leitura. Leitura em voz alta. Rotas de leitura. Traços graduais

\begin{abstract}
This study is based on the Educational Sociolinguistics (BORTONI-RICARDO, 2004), which proposes the treatment of the written word in the assessment of fluency in oral reading based on right and wrong (RASINSKI, 2004). "Error" considering the variants and styles of the language from three continuums: urbanization, orality-literacy and stylistic monitoring. These continuums include the heterogeneity of the language and the social assessment of it, making it possible to identify discontinuous traits, phenomena that receive greater social stigma, and gradual traits present in the orality of almost all BraziliansThis study aims to analyze the transposable variable phenomena for the reading aloud of students of the 6th year of elementary school in two public schools in Sergipe and to verify which reading route these students are accessing that can give us clues of proficiency in reading. The recording session was held, in the academic year of 2016, with 74 students, aged between 10 and 14 years. The analysis was performed in 1 minute of the reading aloud of 2 texts adapted to the curriculum of the reader (DENO, 2003), totaling a corpus of 148 minutes of audio. The results show that it was possible to verify the variable phenomena in the reading aloud and that they can give us clues of the reading routes, allowing to identify the possible proficient readers and not to tax as "error" the erasure of $\mathrm{R}$ in the verbal ending of infinitive or of $\mathrm{S}$ in the nucleus of $\mathrm{SN}$ in the rightmost position or still in the monotongation of / ow / in a reading assessment.
\end{abstract}

Keywords: Reading assessment. Reading out loud. Reading paths. Gradual features.

* Estudante de doutorado na Universidade Federal de Sergipe, professora de Língua Portuguesa do CODAP/UFS. E-mail: alessandrasje@hotmail.com. 


\section{INTRODUÇÃO}

No campo da leitura, os estudos sociolinguísticos de Labov e Robins (1967), Labov et al (1998) e Labov e Baker (2003) compõem um retrato do insucesso na leitura de crianças de classes minoritárias e afro-americanas. Esses estudos contribuíram para a percepção educacional da influência da variação linguística na aprendizagem da leitura.

No Brasil, no campo da Sociolinguística Educacional, Bortoni-Ricardo (2004) trata dos fenômenos variáveis do vernáculo brasileiro presentes em sala de aula. A autora apresenta a teoria dos contínuos para análise da variação linguística na fala de alunos e professores e discute a noção de "erro" e a interferência desses no processo educacional.

Essa abordagem nos interessa na análise da leitura em voz alta de estudantes que transpõem os fenômenos variáveis da fala para a leitura. Considerando que a leitura oralizada está baseada na linguagem falada, esses fenômenos serão como pistas para identificar as estratégias de leitura que os estudantes usam ao acessar as rotas de leitura.

Neste artigo, nosso objetivo é analisar três fenômenos variáveis da fala transpostos para a leitura em voz alta de estudantes do $6^{\circ}$ ano do ensino fundamental de duas escolas públicas de Sergipe e verificar qual a rota de leitura esses estudantes estão acessando, o que pode nos dar pistas da proficiência em leitura.

O texto está estruturado, primeiramente, na discussão da natureza variável da língua e a relação com a leitura em voz alta. Num segundo momento, são apresentados estudos sobre fenômenos variáveis que descrevem um padrão de recorrência na fala espontânea os quais vão contribuir na construção das hipóteses deste artigo.

\section{A NATUREZA VARIÁVEL DA LÍNGUA E A RELAÇÃO COM A LEITURA}

A concepção de língua, linguagem e gramática alinhada à Sociolinguística Educacional (BORTONI-RICARDO, 2004) atende ao sistema variável inerente à língua. Neste sentido, a linguagem é um meio de interação entre os indivíduos que atuam num meio social e numa dada realidade social e historicamente situada. E a gramática atende aos preceitos da descrição, uma vez que descreve as diferentes variedades da língua em uso. A língua é concebida como um sistema heterogêneo e sujeita a variações (GORSKI, FREITAG, 2007).

Essa diversidade da língua está presente na escola que recebe estudantes de realidades sociolinguísticas diferentes. Para atender a essa diversidade, os Parâmetros Curriculares Nacionais (PCN) para o ensino de Língua Portuguesa (LP) alinham-se à concepção de língua enquanto um sistema heterogêneo e variável para "dar conta da variação intrínseca ao processo linguístico" (BRASIL, 1998, p. 60).

Nessa perspectiva de língua heterogênea, os PCN propõem livrar o ensino de LP de alguns mitos, como forma "correta" de falar, "consertar" a fala do estudante, a fala "correta" é a que se aproxima da escrita, e almejam levar o estudante a saber escolher a forma de falar considerando as características e as condições do contexto (BRASIL, 1998, p. 31). A proposta dos parâmetros não é trabalhar com a noção de erro, mas com a adequação de uso às circunstâncias do contexto. 
Esta proposta contra o preconceito e as formas de oralidade e variedades nãopadrão da língua prevê a ressignificação do erro, para a admissão das variedades linguísticas próprias que o estudante traz de seu ambiente familiar. No que concerne às orientações para a leitura de textos escritos, os parâmetros propõem:

leia, de maneira autônoma, textos de gêneros e temas com os quais tenha construído familiaridade:[...]

- articulando o maior número possível de índices textuais e contextuais na construção do sentido do texto, de modo a:

a) utilizar inferências pragmáticas para dar sentido a expressões que não pertençam a seu repertório linguístico ou estejam empregadas de forma não usual em sua linguagem; [...]

d) integrar e sintetizar informações, expressando-as em linguagem própria, oralmente ou por escrito [...] (BRASIL, 1998, p. 50, grifo nosso).

Tomando como base as orientações dos PCN (BRASIL, 1998) para o trabalho da leitura no ensino de Língua Portuguesa, se o estudante ler "causô" em vez de "causou", não seria um problema de erro, mas um fenômeno variável da fala espontânea transposta para a leitura em voz alta.

No entanto, os estudos sobre avaliação de leitura têm mostrado uma postura de língua homogênea, taxando toda variedade que foge ao padrão da escrita como erro. Os estudos norte-americanos (RASISNKI, 2000, 2004a, 2004b; RASISNKI et al, 2005, 2011; HASBROUCK; TINDAL, 2006) e portugueses (TRISTÃO, 2009; FERREIRA, 2009; CASTANHEIRA, 2011) sobre a fluência em leitura oral tomam como base na avaliação da precisão em leitura, entendida como "a análise do processo de decodificação da palavra escrita com automaticidade e com o mínimo de erro", os seguintes parâmetros: pronúncia errada; substituições; reversões e omissões (RASISNKI, 2004, p. 3). Nesta mesma perspectiva de erro e acerto, na área da Psicologia Cognitiva e da Fonoaudiologia, os estudos estão baseados na análise dos processos cognitivos subjacentes à habilidade de leitura. Os estudos de Salles (2005), Pinheiro et al (2008) e Ávila et al (2009) apresentam categorias de erros de decodificação na leitura de palavras isoladas que não levam em consideração a heterogeneidade da língua e os fenômenos variáveis do vernáculo. Esse tipo de avaliação de leitura não atende aos preceitos do ensino de língua norteados pelos PCN que deixam claro a questão do tratamento da "adequação" do uso da língua em detrimento ao "erro".

Uma proposta de avaliação de leitura que atenda aos PCN e a essa natureza variável da língua que está presente em sala de aula pode ser proposta a partir dos estudos de Bortoni-Ricardo (2004, p. 52) que propõem uma análise da variação linguística a partir de três contínuos: de urbanização, de oralidade-letramento, de monitoração estilística. Esses contínuos são representados por uma linha imaginária e em cada extremidade está localizada uma modalidade variável, sustentada pela ideia de que o contínuo serve para mostrar que as fronteiras não são rígidas.

O contínuo de urbanização é representado, em um dos polos, pelas variedades rurais isoladas que representam a fala de moradores rurais ou de pessoas não escolarizadas; na outra extremidade do polo, pelas variedades urbanas padronizadas que 
receberam maior influência da língua padrão. Entre os polos, está a variedade rurbana que é formada pelos migrantes de origem rural que preservam muito de seus antecedentes culturais, apesar de morarem em espaço urbano. O contínuo de oralidade-letramento é um evento em que se apoia em um texto escrito. Isso significa que mesmo numa conversa com amigos, que é um evento de oralidade, num determinado momento em que um dos interlocutores declama uma poesia ou canta uma música, apoiado num texto escrito, acontece um evento de letramento. $\mathrm{O}$ estilo monitorado exige atenção e planejamento do falante. Nesse contínuo, o monitoramento acontece quando a situação exige, porque está num ambiente de letramento, como a sala de aula, ou diante de um interlocutor que exija mais formalidade, como o diretor da escola. De forma contrária, o estilo não monitorado ocorre em interações espontâneas, com o mínimo de atenção à forma escrita da língua (BORTONI-RICARDO, 2004, p. 52-62).

Esses contínuos compreendem a heterogeneidade da língua e a avaliação social desta, possibilitando identificar traços descontínuos, fenômenos que recebem maior estigma social, e traços graduais, presentes na oralidade de quase todos os brasileiros (BORTONI-RICARDO, 2004).

Assim, a leitura em sala de aula, como qualquer outro evento apoiado em um texto escrito, é considerado um "evento de letramento". Esse evento compreende um "estilo monitorado", porque requer planejamento e maior atenção ao texto escrito. Essa análise está representada nos contínuos expressos na figura 1.

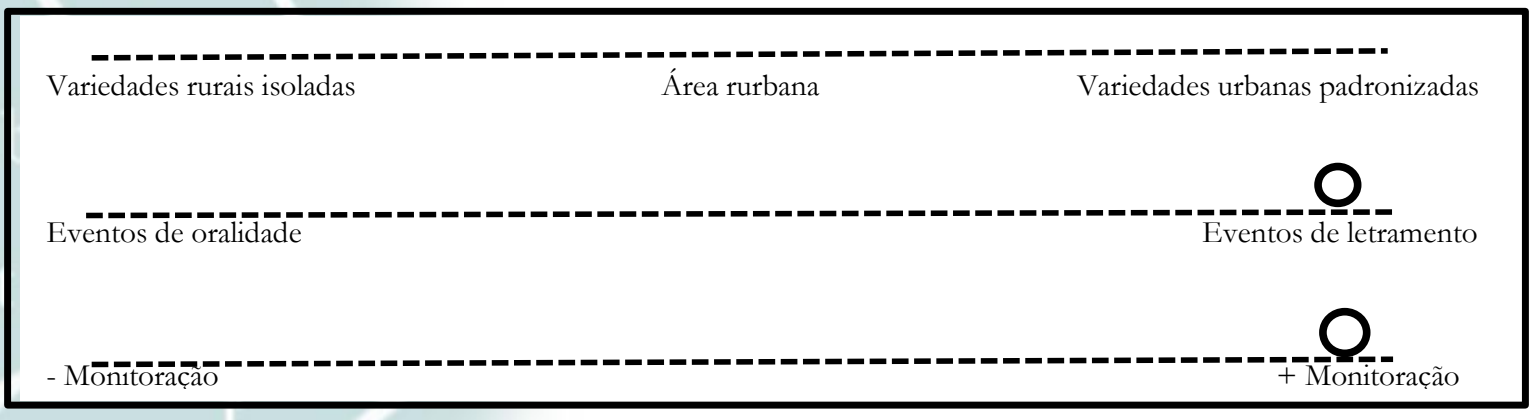

Figura 1: Contínuos de variação linguística.

Fonte: BORTONI-RICARDO, 2004, p. 52-62.

$\mathrm{Na}$ análise da leitura em voz alta pelo contínuo rural-urbano, o leitor pode fazer uso de traços descontínuos e graduais do vernáculo brasileiro, dependendo do acesso às rotas de leitura. Nos estudos sobre leitura e variação linguística, identificamos resultados de fenômenos variáveis transpostos para a leitura em voz alta.

O estudo realizado por Aquino (2011) com 30 estudantes dos $3^{\circ}, 4^{\circ}$ e $5^{\circ}$ ano do ensino fundamental, com objetivo de estabelecer uma tipologia de erros de leitura distribuída em duas categorias: erros influenciados pela variante dialetal e erros de decodificação, a autora verificou que os estudantes do $5^{\circ}$ ano, os mais escolarizados de seu corpus, transpunham mais fenômenos variáveis da fala para a leitura do que os menos escolarizados. Ela identificou esse processo através do acesso à rota lexical, demonstrando que o leitor que já conhecia a palavra escrita e a oralizava em seu vernáculo, enquanto os 
estudantes dos $3^{\circ}$ e $4^{\circ}$ anos faziam uso da rota fonológica e decodificavam as palavras com todas as correspondências grafofonêmicas. Segundo a autora, esses "erros" não comprometeram negativamente o desenvolvimento da leitura.

As rotas de leitura são processos utilizados pelo leitor no reconhecimento da palavra escrita. Esse reconhecimento envolve os processos de acesso às informações grafo fonêmicas e do significado da palavra armazenadas na memória. Nesta perspectiva de estudo, a leitura é compreendida como um processo de automaticidade na decodificação da palavra escrita que leva ao domínio de estratégias para a compreensão do texto lido (LABERGER, SAMUELS, 1974; MORAIS, 1996).

No modelo de dupla rota de leitura, o reconhecimento da palavra escrita acontece mediante dois processos. Na rota lexical, a procura pela palavra envolve o léxico mental que armazena as grafias e as pronúncias; a rota fonológica faz uso de regras que relacionam segmentos ortográficos com segmentos fonológicos, especificamente correspondência entre grafema e fonema (COLTHEART, 2013).

$\mathrm{Na}$ leitura pela rota fonológica, o leitor precisa conhecer as regras de convenção entre grafema e fonema para identificar a forma fonológica da palavra. Se o leitor não tiver o processo de leitura automatizado pode não obter sucesso na leitura de palavras irregulares, que não apresentam uma correspondência unívoca entre grafema e fonema (ex. "táxi", "chá"), diferentemente do que ocorre na leitura de palavras regulares, correspondência unívoca entre letra e som (COLTHEART, 2013).

$\mathrm{Na}$ rota lexical, geralmente utilizada por leitores que já têm o processo de decodificação automatizado, é necessário que o leitor reconheça as palavras que estão armazenadas no léxico mental. Lupker (2013, p. 57) explica que "a memória lexical, ou 'léxico', é um dicionário mental que contém entradas para todas as palavras que um leitor conhece". A leitura se dá por uma forma direta em que a imagem impressa armazena todas as informações como num dicionário. O leitor reconhece o léxico ortográfico (táxi), que armazena as informações do léxico fonológico (a pronúncia da palavra), o conhecimento gramatical (substantivo masculino) e semântico (transporte de pessoas). O leitor que faz uso da rota lexical já conhece a palavra escrita e pode oralizá-la conforme seu reportório linguístico.

Nos estudos de Coltheart e seus colaboradores (2013) sobre o que o modelo de dupla rota de leitura conseguia explicar sobre a leitura em voz alta, eles identificaram que:

a) palavras de alta frequência são lidas em voz alta com mais rapidez do que palavras de baixa frequência;

b) palavras são lidas em voz alta com mais rapidez do que não palavras ${ }^{1}$;

c) palavras regulares são lidas em voz alta com mais rapidez do que palavras irregulares;

d) o tamanho da vantagem da regularidade é maior para palavras de baixa frequência do que para palavras de alta frequência [...] (COLTHEART, 2013, p. 33).

\footnotetext{
${ }^{1}$ Não palavra é a sequência de letras organizadas de acordo com a estrutura de uma palavra, mantendo relações de semelhança formal, mas não possui um significado, por exemplo "exercico", "fetre" (COLTHEART, 2013).
} 
Considerando o acesso à rota lexical e os fenômenos variáveis da fala na leitura em vOz alta, podemos inferir que os fenômenos variáveis na leitura poderão ser identificados no uso de palavras de alta frequência. Isto significa que quanto mais palavras do texto escrito fizerem parte do repertório lexical dos leitores, mais acesso à rota lexical de leitura será possível, melhorando a velocidade e a precisão na leitura em voz alta.

Assim, verificar os fenômenos variáveis na leitura em voz alta dos estudantes do $6^{\circ}$ ano do ensino fundamental pode nos dar pistas das rotas de leitura, que possibilitam identificar os possíveis leitores proficientes. A identificação do uso da rota fonológica de leitura pode se dar pela leitura desvinculada da língua como vernáculo do contexto sóciohistórico-cultural em que a língua é produzida; já o acesso à rota lexical é possível identificar que o leitor conhece a palavra lida, principalmente, se essa for expressa na linguagem própria do leitor. É bom deixarmos claro que se o leitor não fez uso de fenômenos variáveis da fala na leitura em voz alta que esteja acessando somente a rota fonológica. Salles e Parente (2007) mostraram em seus estudos que os leitores proficientes coordenam o uso das rotas fonológica e lexical na leitura oralizada.

A partir dessa discussão surge-nos uma questão, levando em consideração o sistema heterogêneo da língua, os contínuos de variação e de estilo da língua e os traços graduais e descontínuos, quais os fenômenos variáveis podem ser identificados de forma recorrente na leitura em voz alta de estudantes do $6^{\circ}$ ano do ensino fundamental? Considerando ainda que fenômenos variáveis da fala na leitura em voz alta não prejudicam a compreensão da leitura (AQUINO, 2011), a ocorrência de fenômenos variáveis na leitura pode dar pistas da proficiência em leitura?

Para tentar responder essas questões, vamos trabalhar com três fenômenos variáveis da fala que são transpostos para a leitura em voz alta: monotongação, apagamento do R em coda silábica e concordância nominal e a relação desses fenômenos com o acesso às rotas de leitura.

\section{FENÔMENOS VARIÁVEIS DA FALA}

Apresentamos os contextos de variação - monotongação, apagamento do $\mathrm{R}$ em coda silábica e concordância nominal - a partir de resultados de estudos de fala espontânea, a partir dos quais passamos à construção de nossas hipóteses para a sua recorrência na leitura. Do ponto de vista dos contínuos, os fenômenos são configurados como traços graduais. Apresentamos, primeiramente, os fenômenos variáveis que estão no vernáculo do brasileiro e não sofrem estigma social. Em seguida, tratamos do fenômeno que sofre estigma social, no entanto está presente na fala dos brasileiros.

Iniciamos a descrição com o fenômeno variável da monotongação. Para compreendermos esse processo, primeiramente, temos que identificar o que é um ditongo. O ditongo é formado por uma sequência de segmentos representada por vogal e semivogal ou glide pronunciada numa mesma sílaba. A semivogal ou glide é a vogal sem proeminência de acento nos ditongos. Neste sentido, ditongo "consiste de uma sequência de segmentos vocálicos sendo que um dos segmentos é interpretado como vogal e o outro como um glide" (SILVA, 2015, p. 94). Numa sequência de vogal-glide, o ditongo é 
denominado de decrescente, como em "causou" formado por dois ditongos decrescentes / au/ e /ow/. Segundo Câmara Júnior (1991), o apagamento da semivogal de um ditongo decrescente oralizado pode produzir um monotongo (/ow/ para /o/) no português. A monotongação é o processo em que a vogal não apresenta mudança de qualidade (SILVA, 2015). Esse processo ocorre com o apagamento das semivogais "i" e "u" de ditongos, representadas fonologicamente pelos glides /y/ e /w/, respectivamente, na oralização da palavra escrita com ditongo, como em "dinhêro" ao invés de "dinheiro" e "hôve" no lugar de "houve".

O estudo do processo de monotongação com dados de fala espontânea tem sido abordado por vários estudiosos. Neste artigo, tomamos como base os estudos com dados de fala espontânea de Carvalho (2007), com informantes recifenses; de Jesus et al (2010), com dados de universitários de Itabaiana/SE; e estudos com dados de leitura de Aquino (2011), Hora e Aquino (2012) e Catete et al (2016) cujo estudo foi realizado com parte dos dados desta pesquisa na leitura em voz alta dos estudantes dos $6^{\circ}$ e $9^{\circ}$ anos do Colégio Estadual Ministro Petrônio Portela (CEMPP).

Para Carvalho (2007), a questão do apagamento do ditongo já é uma realidade no vernáculo brasileiro e possivelmente se encontra internalizado entre os falantes. A autora trabalhou com dados de fala espontânea (narrativas pessoais coletadas através de entrevistas sociolinguísticas) e fala controlada (leitura de lista de palavras e de um texto elaborado pela autora com palavras de uso diário) e justifica a afirmativa da internalização desse fenômeno com os resultados da aplicação da regra variável em ambos os estilos (fala espontânea e controlada) do corpus, ou seja, os fenômenos variáveis já estão presentes na leitura também.

Esses resultados também são encontrados na pesquisa de Jesus et al (2010) com dados de fala de estudantes universitários sobre a monotongação de ditongos ei e ou com universitários do campus da Universidade Federal de Sergipe (UFS) em Itabaiana-SE. Os autores concluíram que, nesse corpus, os universitários fazem uso frequente da monotongação. A depender do fator controlado, percebeu-se que na situação espontânea (fala) a perda da semivogal foi mais frequente do que na situação controlada (quando os estudantes liam o questionário).

No campo da leitura oralizada, os resultados de Aquino (2011) apontam que, em todos os anos pesquisados, ocorreram todos os tipos de fenômenos variáveis previamente estabelecidos no estudo: apagamento do $\mathrm{R}$ na coda silábica, ditongação, rotacismo, monotongação, apagamento do /d/ no grupo -ndo, simplificação do grupo consonantal e concordância nominal. Ao verificar a ocorrência desses fenômenos na leitura, sobre a monotongação dos ditongos decrescentes, o ditongo /ow/ apresentou maior apagamento do glide. $\mathrm{Na}$ análise da variável social, constatou que esse fenômeno não sofre estigmatização e que apresenta maior ocorrência no corpus.

Neste mesmo sentido da identificação de fenômeno variável da fala espontânea na leitura, os estudos de Hora e Aquino (2012), que analisaram ditongação, monotongação e apagamento do "d" no grupo -ndo, na oralização de texto escrito de 30 estudantes do $3^{\circ}$, $4^{\circ}$ e $5^{\circ}$ ano, os resultados de monotongação dos ditongos [ey] e [ow] dos estudantes mais escolarizados do corpus ( $5^{\circ}$ ano) apresentaram maior tendência à aplicação na leitura das 
mesmas regras do fenômeno variável na fala espontânea. Diferentemente desse resultado, no estudo de Catete et al. (2016) sobre a leitura em voz alta de 82 estudantes dos $6^{\circ}$ e $9^{\circ}$ anos do ensino fundamental, constataram que o processo de monotongação foi mais recorrente nos estudantes dos $6^{\circ}$ anos, menos escolarizados naquele corpus.

Apresentado o fenômeno fonológico de monotongação, passemos ao fenômeno variável de natureza morfológica, apagamento do $\mathrm{R}$ em coda silábica no final e no meio de sílaba. $\mathrm{O}$ apagamento do $\mathrm{R}$ em coda silábica é um fenômeno verificado na fala espontânea brasileira, como em "para podê comê todos os doces" ao invés de "para poder comer todos os doces".

No estudo com dados de fala espontânea, Mollica e Fernandez (2003) investigaram progressividade ou estabilidade no processo de apagamento do $\mathrm{R}$ em coda silábica, num estudo em tempo aparente e tempo real. Os dados fazem parte de uma amostra da década de 80/84 que foram comparados com dados de outra coleta, do ano 2000, realizada com alguns informantes que fizeram parte da primeira amostra. $O$ estudo aponta para a estabilidade fonológica do processo variável de apagamento do $\mathrm{R}$ em final de formas verbais, uma vez que os dados exibem maior ocorrência, expandindo-se posteriormente para os nomes (substantivos e adjetivos).

No estudo de Reis e Dias (2006), foi investigado o apagamento do R em coda silábica de verbos no infinitivo. Os autores mostraram evidências do apagamento de marca redundante, uma vez que os falantes apagam o $\mathrm{R}$ da forma nominal do verbo no infinitivo impessoal por este acumular dois traços: tonicidade (vocábulos oxítonos) e morfema $\mathrm{r}$ (desinência modo temporal), caracterizando o fonema / r/ como uma categoria duplamente marcada. O estudo longitudinal descreveu dados coletados de fala espontânea de crianças em fase final de aquisição da linguagem (2 a 7 anos). Os resultados demonstraram praticamente categórica a aplicação da regra de apagamento do $\mathrm{R}$ no verbo no infinitivo. Os autores ainda discutem que se firmar este apagamento na fala de informantes crianças, fica evidenciada a possibilidade de uma possível mudança na articulação oral do respectivo fonema na categoria verbo.

Nesse mesmo sentido de falantes apresentarem maior apagamento de $\mathrm{R}$ no infinitivo, Oushiro e Mendes (2014) estudaram a realização variável de R em coda silábica com dados de fala espontânea de 118 paulistanos, de 20 a 60 anos. O tipo de coleta apresenta diferentes graus de monitoramento de fala que vai da conversação mais espontânea ao estilo mais cuidadoso (leitura de textos e palavras). Os resultados corroboram com os outros estudos e mostram que a sua realização só se dá na leitura de textos e listas de palavras, em que os vocábulos com $\mathrm{R}$ em coda foram todos grafados de acordo com a ortografia padrão - "ver" e não "vê", "cobrar" e não "cobrá", "erguer" e não "erguê'. Os autores concluem que esse fenômeno variável não é transposto para a leitura, porque "se trata da pressão normativa e da ideologia escolar, imposta sobre o vernáculo dos falantes, que prescreve que o modo "correto" de falar é tal qual se escreve" (OUSHIRO e MENDES, 2014, p. 262).

Nos estudos de Callou et al. (2015) sobre o apagamento do R em coda silábica, as autoras apontam a necessidade do estudo separadamente em coda medial e final. Assim como Reis e Dias, Callou e colaboradores também defendem a hipótese de que esse 


\section{Revista

processo seja uma "marca morfológica de caráter redundante", uma vez que as formas verbais do infinitivo recebem acento tônico na última sílaba. O estudo foi realizado com falantes mais escolarizados das nove capitais do Nordeste com dados de momento mais informal das entrevistas do Projeto Atlas Linguístico do Brasil (Projeto ALiB), coletadas no ano de 2000. Os resultados mostram maior apagamento do $\mathrm{R}$ em coda silábica final em verbos $(94 \%)$ e não verbos $(72 \%)$ e a manutenção em coda silábica medial $(90 \%)$. Aracaju foi uma das capitais que menos apagou o R em coda silábica de verbos (83\%) e não verbos $(53 \%)$.

Outro estudo relevante para o levantamento de nossa hipótese foi realizado por Araújo et al (2016) e Pinheiro et al (2017) que utilizaram parte dos dados deste artigo referentes à coleta da leitura em voz alta de estudantes dos $6^{\circ}$ e $9^{\circ}$ anos do ensino fundamental do CEMPP. Os autores chegaram a resultados que apontaram maior ocorrência de apagamento do $\mathrm{R}$ em coda final de verbos, devido à condição morfológica favorável, e que mostram que "esse processo, comum à oralidade, por não sofrer estigmatização social, está se cristalizando no inventário da Língua Portuguesa, visto ter alcançado um ambiente de maior formalidade e rigor, como a leitura oral" (ARAÚJO et al, 2016, p. 300).

Retomando os aportes teóricos dos contínuos de Bortoni-Ricardo (2004) e das rotas de leitura de Coltheart (2013) para análise de pistas que mostrem a proficiência em leitura através de fenômenos variáveis da fala na leitura em voz alta, verificamos que os dois primeiros fenômenos, monotongação de ei e ou e apagamento do $\mathrm{R}$ em coda de verbos no infinitivo, são caracterizados como traços graduais da fala espontânea por se encontrarem no repertório de praticamente todos os brasileiros, independentemente de seus antecedentes geográficos (rural ou urbano e região do país). No contínuo de oralidade-letramento, verificamos que esses fenômenos ocorrem de forma categórica nas interações de fala espontânea e que passam da fala para a leitura que é um evento de letramento por estar apoiado em texto escrito. E nesse contínuo é exigido um estilo de maior monitoramento, planejamento e atenção à língua escrita, no entanto, identificamos fenômenos variáveis da fala na leitura. Levando em consideração o padrão de recorrência desses fenômenos, levantamos a hipótese de que a transposição desses fenômenos para a leitura em voz alta pode ser explicada pelo acesso à rota lexical.

$\mathrm{Na}$ realização da monotongação dos ditongos ei e ou na leitura em voz alta, a nossa hipótese é de que o leitor proficiente acessa a rota lexical, independentemente do tipo de ditongo, porque esse fenômeno variável tem se mostrado regra categórica nos estudos de fala espontânea e de leitura oralizada, ou seja, é um fenômeno já consolidado na fala e não sofre estigma social.

Quanto ao apagamento do $\mathrm{R}$ em coda silábica, construímos a hipótese de que o leitor transpõe esse fenômeno da fala para a leitura em voz alta na realização do apagamento do R em coda silábica final de verbo e da manutenção em coda sílaba medial, porque está acessando a rota lexical de leitura. Isto se deve à consolidação desse fenômeno no vernáculo brasileiro, mostrando que o leitor acessa a palavra de forma direta no léxico mental, uma vez que já a conhece. 
O terceiro fenômeno variável alvo de nosso estudo da fala espontânea é a concordância nominal de número para a análise da realização de marca de plural nos elementos do sintagma nominal (SN).

Nesse fenômeno de natureza sintática, a realização da marca de plural nos elementos do SN é regra geral na concordância nominal da LP, quando o núcleo estiver no plural, como em "os doces". A concordância consiste em adequar os itens determinantes à palavra determinada, no entanto, no vernáculo brasileiro, "os doce" tem se tornado uma regra variável, uma vez que há a possibilidade de não ocorrer a flexão de todos os elementos do sintagma.

Scherre (1997) e Scherre e Naro (1998, 2006) têm estudado sobre a flexão de número do $\mathrm{SN}$ com dados de fala espontânea de falantes do Rio de Janeiro e mostraram que a alternância de itens flexionados se deve não só à eliminação da redundância das regras. Tomemos os resultados desses trabalhos que interessam à análise deste estudo.

No estudo com 68 falantes do corpus Censo, Scherre (1997) analisou a concordância nominal sob duas perspectivas: a atomística, em que cada elemento flexionável do SN é uma unidade de análise, e a não-atomística, em que o SN inteiro é a unidade de análise. Os resultados mostraram que, na configuração do tipo de $\mathrm{SN}$, as variantes explícitas de plural atendem à configuração [quantificador + artigo definido + substantivo] ("todos os doces"), que contém dois elementos de referência globalizante juntos. Quanto à variável social, todos os falantes de qualquer nível de escolarização apresentam essas estruturas com um índice alto de variantes explícitas: os de 9 a 11 anos de escolarização com 83\%; os de 5 a 8 com $81 \%$; e os de 1 a 4 anos com $76 \%$.

$\mathrm{Na}$ análise da concordância nominal com foco na saliência fônica e na posição, Scherre e Naro (1998), no Corpus Censo do Programa de Estudos sobre o Uso da Língua (PEUL), verificaram que, de forma geral, todos os itens mais salientes (plural irregular) favorecem mais a presença de marcas explícitas de plural nos elementos nominais dos SNs (ex. no final de semana - nos finais de semana). Os menos salientes (os regulares) favorecem menos a presença de marcas explícitas.

$\mathrm{Na}$ variável posição dos elementos nominais em relação ao núcleo do SN, os autores verificaram que elementos nucleares ou não nucleares do SN na "posição à esquerda - a posição de proeminência tópica - favorece mais marcas explícitas de plural do que a posição à direita” (SCHERRE, NARO, 1998, p. 10).

Os estudos de fala espontânea sugerem que existe um sistema estruturado ditando a variação na concordância nominal de número no vernáculo brasileiro; sendo, portanto, possível prever em que estruturas linguísticas e em que situações sociais os falantes são mais propensos a usar ou apagar as marcas formais de plural nos elementos flexionáveis do SN (SCHERRE, NARO, 1998, p. 13). No entanto, a falta de realização da marca de plural indica uma fala sem prestígio social entre os falantes.

$\mathrm{Na}$ amostra de Scherre e Naro (2006), com análises comparativas de três conjuntos de dados da comunidade de fala do Rio de Janeiro, os resultados apresentados indicam que, "para este fenômeno variável estigmatizado, atuam com igual vigor restrições sociais, como força propulsora em direção à norma padronizada, e forças estruturais, como 
mantenedoras da heterogeneidade ordenada do sistema vigente" (SCHERRE; NARO, 2006, p. 115).

A falta de prestígio social é verificada na análise das variáveis sociais: escolaridade, sexo e faixa etária. Os autores verificaram que a falta de marca explícita de plural na concordância nominal é sensível à estigmatização pelos padrões gramaticais. Verificou-se que a variação na concordância do português falado no Brasil está internalizada na mente dos falantes e se trata de uma variação estruturada em função de aspectos linguísticos e sociais (SCHERRE; NARO, 1998).

Quanto aos aspectos sociais, apresentam mais a variante explícita as pessoas com mais anos de escolarização (exposição à correção gramatical) e as do sexo feminino (propensão a seguir as normas de prestígio). A faixa etária mostra que as pessoas mais pressionadas pela idade profissionalmente produtiva usam também mais as formas de prestígio. O comportamento destas três variáveis convencionais indica um padrão típico de variação estável, apesar de um maior refinamento das variáveis revelar que há também indícios de perda e de aquisição das variantes explícitas de plural (SCHERRE; NARO, 1998, p. 11).

Nos estudos com dados de leitura (AQUINO, 2011), os resultados mostram que as formas variantes da fala são transpostas para a leitura e, com maior ocorrência, principalmente, aquelas que não são estigmatizadas. Neste sentido, esse fenômeno variável apresentou resultados consonantes com os resultados de língua falada, com a realização de maior ocorrência da marca de plural no núcleo em primeira posição (mais à esquerda) do que em outras. Como o corpus para análise desse fenômeno variável era pequeno, a autora fez uma análise qualitativa não-atomística das poucas construções da amostra.

Retomando os pressupostos dos contínuos de Bortoni-Ricardo (2004) e as rotas de leitura de Coltheart (2013), podemos verificar que esse fenômeno variável caracteriza-se como um traço gradual, pois aparece no polo rural do contínuo, mas também nas comunidades rurbanas e urbanas. Apesar de receber uma avaliação negativa na falta da marca de plural de elementos do SN, esse fenômeno é uma regra bastante incorporada pelos falantes, mesmo os mais escolarizados omitem a marca de plural em elementos na posição mais à direita do $\mathrm{SN}$, evitando a marca de maneira redundante do plural, e em elementos menos salientes do SN. Na leitura em voz alta, no contínuo de letramento, em estilo mais monitorado, Aquino (2011) identificou esse fenômeno na leitura de estudantes.

Tomando esses dados, podemos levantar algumas hipóteses em relação às estratégias de leitura e o fenômeno variável: se o leitor omitir marcas de concordância em elementos nucleares na posição mais à direita ou em elementos menos salientes, podemos inferir que ele está acessando a rota lexical, demonstrando ter internalizado as regras estruturantes do uso vernacular do fenômeno, mesmo num ambiente que exige monitoramento. Acreditamos que esse uso é mais recorrente nos informantes do sexo masculino. 


\section{O PROCESSO DE COLETA DA LEITURA EM VOZ ALTA}

Os dados analisados neste estudo foram coletados em duas escolas públicas de Sergipe, Colégio de Aplicação da Universidade Federal de Sergipe (Codap/UFS) e Colégio Estadual Ministro Petrôneo Portela (CEMPP). Compõem essa amostra dados de leitura em voz alta de 74 estudantes do $6^{\circ}$ ano do ensino fundamental, 43 do Codap/UFS e 31 do CEMPP, com idade entre 10 e 14 anos (CAAE 2.008.797).

Essa coleta ocorreu no início do ano letivo de 2016, respeitando o calendário escolar das escolas participantes, e a sessão de gravação da leitura em voz alta de dois textos para cada estudante foi realizada em ambiente reservado e de forma individual. Os textos utilizados para a leitura foram selecionados a partir de livros didáticos dos $6^{\circ}$ anos do Programa Nacional do Livro Didático (PNLD) de 2014. Esses procedimentos atenderam ao método de coleta baseado no Curriculum-Based Measurement (DENO, 2003), respeitando os seguintes procedimentos: texto adequado ao nível de escolaridade do leitor; leitura em voz alta de dois textos; mensuração pequena e eficiente, com análise de 1 minuto de leitura.

Os áudios foram editados, no programa Audacity, em 1 minuto, contando do início da leitura do texto pelo estudante. As transcrições foram realizadas no programa ELAN que possibilitou revisitar os dados para apurar as análises e atenderam às normas de transcrição ortográfica do Banco de Dados Falares Sergipanos (FREITAG, 2013).

Identificamos nos textos usados para a leitura em voz alta os possíveis contextos de realização de fenômenos variáveis objetos deste estudo (quadro 1).

\begin{tabular}{|c|c|}
\hline Processo & $\begin{array}{c}\text { Palavras /Quantidade (Obs.: quando a palavra aparece mais de uma vez, colocamos a } \\
\text { quantidade entre parênteses) }\end{array}$ \\
\hline Monotongação & $\begin{array}{l}\text { coisas, muito (2), desejou, dinheiro (2), leite (3), gostei, primeira (2), primeiras, bairro, finais, } \\
\text { mais, coisas, jeito, muita, causou, houve, causa, cheguei, financeiras, cheio, meu (2), Eunice } \\
\text { (4), seu (2), cheio, infância, experiência, experiências, especiais, pai, foi (3) }\end{array}$ \\
\hline $\begin{array}{l}\text { Apagamento do } \\
\text { rótico em } \\
\text { coda silábica - } \\
\text { final de palavra }\end{array}$ & $\begin{array}{l}\text { comprar (2), furar (2), cozinhar, ter (4), poder (2), comer, vender, poder (2), saber, escolar, } \\
\text { particular, familiar, fazer, ler, escrever, }\end{array}$ \\
\hline $\begin{array}{l}\text { Apagamento do } \\
\text { rótico em } \\
\text { coda silábica - } \\
\text { meio de palavra }\end{array}$ & $\begin{array}{l}\text { tarde (2), perto, porta, particular, marcada, harmonia, partiu, marca, termo, portanto, porque } \\
\text { (3) }\end{array}$ \\
\hline $\begin{array}{l}\text { Concordância } \\
\text { nominal }\end{array}$ & $\begin{array}{l}\text { todos os dias, todos os doces, todas as crianças, todas as vezes, todas as latinhas, as latinhas, } \\
\text { as latinhas e eu furava todas, os doces, nos finais, uns oito anos, as crianças, nessas coisas, } \\
\text { aos } 6 \text { anos, dificuldades financeiras, palavras e frases ligadas, das minhas primeiras } \\
\text { experiências, suas salas, suas características especiais, árvores frondosas, palavras e frases } \\
\text { ligadas. }\end{array}$ \\
\hline
\end{tabular}

Quadro 1: Relação dos traços variáveis: texto 1 "A menina e as balas" e texto 2 "Que saudade da professorinha”.

Fonte: Elaborado pela autora com dados da pesquisa.

Após a codificação e quantificação dos dados, realizamos tratamento estatístico descritivo e inferencial, com teste qui-quadrado (chisq.testr) e regressão logística (glm) para verificar efeitos das variáveis na ocorrência em leitura. 


\section{A VARIAÇÃO LINGUÍSTICA NA LEITURA EM VOZ ALTA: OS RESULTADOS}

$\mathrm{Na}$ identificação dos fenômenos variáveis na leitura em voz alta, inicialmente verificamos a ocorrência dos traços analisados expressos na tabela 1.

\begin{tabular}{lccc}
\hline \multicolumn{1}{c}{ Fenômenos } & $\begin{array}{c}\text { Ocorrências } \\
\text { encontradas }\end{array}$ & $\begin{array}{c}\text { Ocorrências } \\
\text { excluídas }\end{array}$ & $\begin{array}{c}\text { Ocorrências } \\
\text { analisadas }\end{array}$ \\
\hline Monotongação & 216 & 6 & 210 \\
\hline R em coda silábica & 791 & & 791 \\
\hline Concordância nominal & 1725 & 2 & 1723 \\
\hline
\end{tabular}

Tabela 1: Ocorrências de traços variáveis na leitura em voz de estudantes do $6^{\circ}$ ano do ensino fundamental.

Fonte: Elaborada pela autora com dados da pesquisa.

As ocorrências excluídas correspondem à realização do fenômeno variável, porém não correspondem à palavra escrita do texto, como "cansô" ao invés de "causô" ou "causou". Na leitura em voz alta, encontramos maior ocorrência de traços variáveis na concordância nominal (1725), seguida de R em coda silábica (791) e monotongação (216).

\subsection{MONOTONGAÇÃO}

O processo de monotongação é resultante do apagamento das semivogais [y] e [w] dos ditongos ei e ou, ocasionando a redução do ditongo. A amostra apresentou maior incidência no texto 2 , com as seguintes palavras que compõem o corpus de análise deste estudo: "causou" e "houve" - verbos - e "financeiras" e "primeira" - nomes.

Os resultados evidenciam a realização do processo de monotongação dos dois ditongos na amostra.

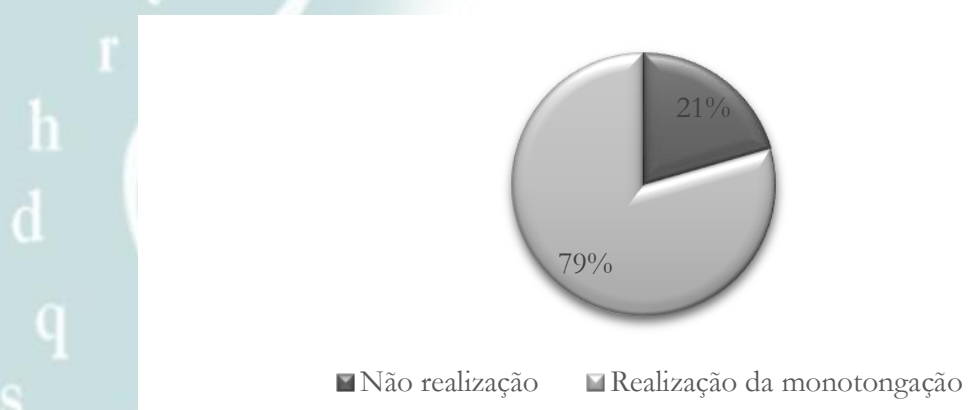

Gráfico 1: Ocorrência de monotongação na amostra. Fonte: Elaborado pela autora com dados da pesquisa.

Verificamos que $79 \%$ dos estudantes do $6^{\circ}$ ano realizaram a monotongação na leitura em voz alta (Gráfico 1). Esse dado nos mostra que a ocorrência desse fenômeno está consolidada na fala do brasileiro (CARVALHO, 2007) e na leitura. Verificamos esse 
resultado em outros estudos com dados de leitura oral: em Aquino (2011), 68,46\% dos estudantes do $5^{\circ}$ ano, maior escolaridade do corpus, também suprimem o glide dos ditongos. Os resutados de Catete et al (2016) também seguem essa direção: 66,7\% dos estudantes do $6^{\circ}$ ano e 50,9\% do $9^{\circ}$ ano monotongam os ditongos na leitura em voz alta.

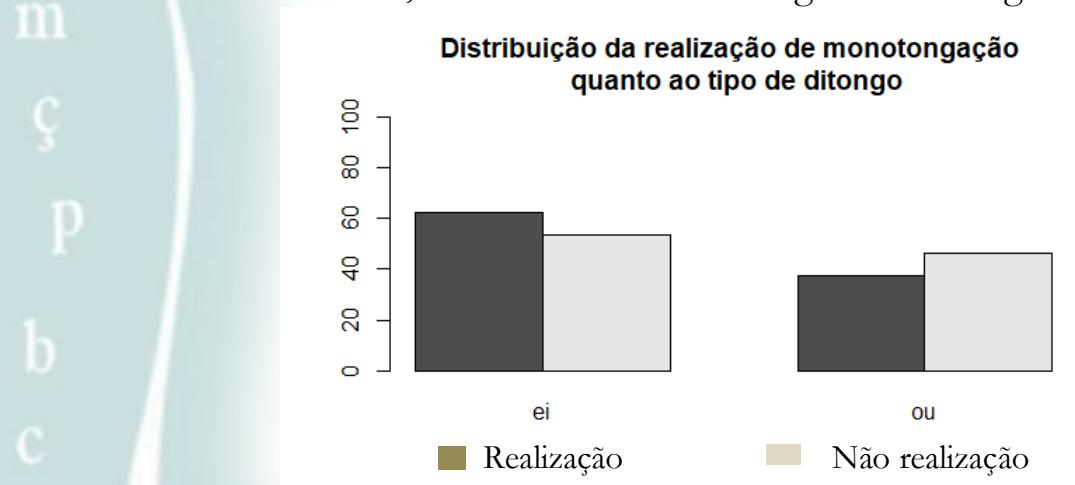

Gráfico 2: Realização de monotongação com os ditongos “ei” e “ou”.

Fonte: Elaborado pela autora com dados da pesquisa.

Dos $79 \%$ das realizações de ditongos do corpus monotongados, 61\% são referentes aos ditongos "ei" e 39\%, aos ditongos "ou", levando em consideração a frequência desses no corpus que corresponde a 127 ditongos “ei” e 82 “ou” (Gráfico 2).

No estudo de Carvalho (2007), o apagamento do ditongo /ow/ apresentou-se de forma categórica na fala. $\mathrm{Na}$ análise da variável contexto de realização, de acordo Jesus et al (2010), na fala, o monotongo é mais recorrente quando o ditongo for acompanhado por " $\mathrm{r}$ ", como em "financeiras" e "primeira". Já o ditongo "ou” reduz ao monotongo em quaisquer contextos, independentemente das variáveis sociais: sexo, faixa etária e anos de escolarização. Nos dados de leitura de Aquino (2011), a monotongação do "ou" foi mais recorrente. Os resultados de Catete et al (2016) mostram que as ocorrências de monotongo nos textos dos $6^{\circ}$ anos foram nos vocábulos "dinheiro", "primeira", "financeiras", "causou" e "desejou", suprimindo o glide na leitura oral dos contextos / ey/ e /ow/.

Relacionando os resultados verificados na leitura em voz alta e a estratégia de leitura usada pelos estudantes do $6^{\circ}$ ano, podemos confirmar nossa hipótese. $\mathrm{O}$ acesso à rota lexical pode ser explicado por esse fenômeno variável ser de uso consolidado como traço gradual tanto em estudos de fala espontânea (CARVALHO, 2007; JESUS et al, 2010) quanto em estudos de fenômenos variáveis na leitura (AQUINO, 2011; HORA, AQUINO, 2012; CATETE et al, 2016). O uso da rota lexical nos mostra que o leitor conhece as palavras lidas, internalizou as regras dos fenômenos variáveis e acessou o léxico de forma direta, mostrando automaticidade no processo de decodificação do texto lido.

Os resultados obtidos confirmar a realização da monotongação na leitura em voz alta, independentemente, dos contextos dos ditongos ("ei" e "ou"), confirmando nossa hipótese. Esse fenômeno variável tem se mostrado regra categórica nos estudos de fala espontânea e de leitura oralizada, por ser um fenômeno já consolidado na fala e não sofrer 
estigma social. Como um traço gradual, o leitor acessa a rota lexical, confirmando nossa hipótese de que há uma correlação entre o fenômeno variável e o acesso à rota lexical. Essa rota de leitura somente é acessada por leitores proficientes que têm um certo repertório lexical.

\subsection{APAGAMENTO DO R EM CODA SILÁBICA}

$\mathrm{O}$ apagamento do $\mathrm{R}$ em coda silábica na leitura em voz alta foi relacionado às variáveis posição - no final e no meio de sílaba - e classe gramatical - verbos ("comprar", "furar", "poder", "comer", "ter", "cozinhar", "vender" e "saber"), nomes ("tarde”, "perto" e "porta") e palavras de ligação ("porque", "por"). Os resultados do apagamento do R em coda silábica estão expressos no gráfico 3.

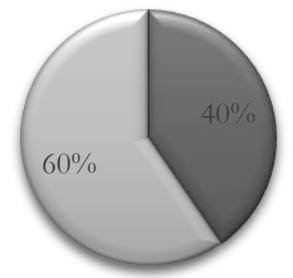

- Apagamento do R $\square$ Não apagamento do R

Gráfico 3: Realização do apagamento do R em coda silábica no corpus.

Fonte: Elaborado pela autora com dados da pesquisa.

Os resultados mostram que houve menos realização do fenômeno variável na leitura em voz alta, uma vez que $40 \%$ dos leitores apagaram o R em coda silábica, enquanto $60 \%$ não realizaram o apagamento.

Quanto à posição na sílaba, o apagamento apresenta maior ocorrência no final de sílaba (Gráfico 4).

\section{Distribuição da realização de $\mathbf{R}$ em coda silábica}

quanto à posição

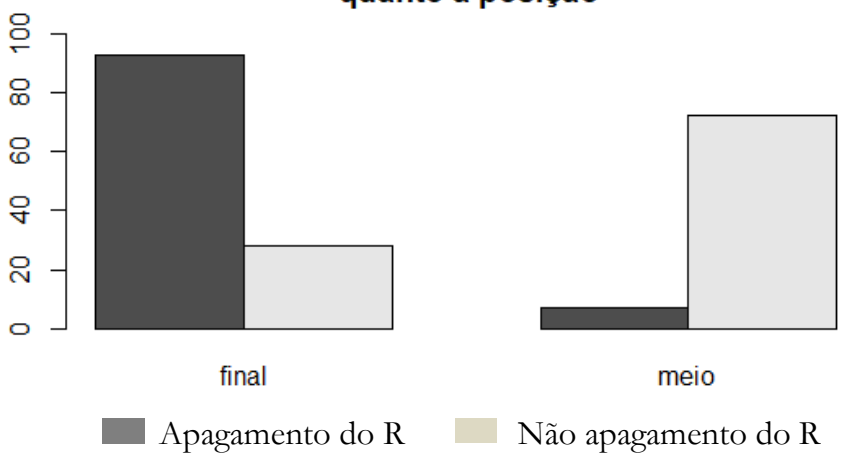

Gráfico 4: Apagamento do R em coda silábica quanto à posição da sílaba.

Fonte: Elaborado pela autora com dados da pesquisa. 
Os estudos de fala espontânea mostram uma relação entre as variáveis posição e classe gramatical (CALLOU et al, 2015). Quanto à variável classe gramatical, houve maior ocorrência de apagamento em verbos no infinitivo, como em "comprá" ao invés de 'comprar (Gráfico 5).

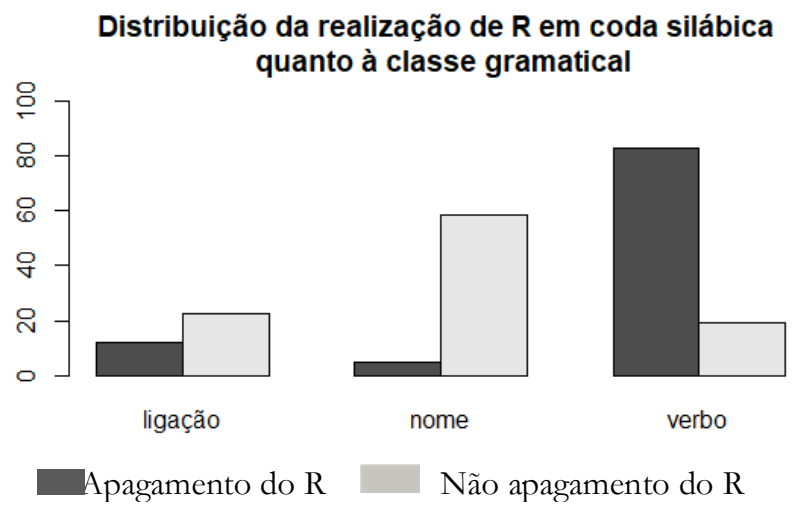

Gráfico 5: Apagamento do R em coda silábica quanto à classe gramatical. Fonte: Elaborado pela autora com dados da pesquisa.

$\mathrm{Na}$ oralização da palavra escrita, há maior conservação do R em coda silábica de nomes. É importante ressaltar que os nomes nesta amostra são todos de sílaba medial ("tarde", "perto" e "porta") que apresentaram maior conservação do R na análise quanto à posição da sílaba (gráfico 4). No entanto, há maior apagamento em verbos no infinitivo em que que o R está na posição final.

Nos estudos com dados de fala espontânea, Oushiro e Mendes (2014) verificaram que, num total de mais de 68 mil dados, o apagamento é a variante mais frequente $(56,3 \%)$ e que o apagamento do $\mathrm{R}$ foi altamente favorecido na fala mais espontânea e, inversamente, desfavorecido nos estilos de leitura (maior atenção do informante à própria fala). Neste mesmo sentido de realização do fenômeno, Mollica e Fernandez (2003), Reis e Dias (2006) e Callout et al (2015) mostraram que a regra do fenômeno variável de pagamento do $\mathrm{R}$ no final de sílaba das formas verbais está bem estável na fala.

Nos resultados com dados de leitura, Pinheiro et al (2017) verificaram que a taxa de apagamento do $\mathrm{R}$ foi de 70,5\%, enquanto a de manutenção foi de 29,5\% dos casos. Esses resultados apontam que o fenômeno, assim como na fala, também ocorre na leitura oral de maneira predominante. Aquino (2011) também constatou que a forma de apagamento do $\mathrm{R}$ foi mais recorrente do que a manutenção, apesar de Oushiro e Mendes (2014) detectarem maior monitoramento nos dados referentes ao estilo controlado (leitura de textos e palavras).

A regressão logística aponta tendência maior ao apagamento do $\mathrm{R}$ em verbos no infinitivo, como em "comprá", "furá", "podê", "comê" e "sabê" e menor ocorrência de realização no meio de sílabas, como em "poquê (Tabela 2). 


\section{Revista

\begin{tabular}{|c|c|c|c|c|}
\hline & Estimate std. & Error & z value & $\operatorname{Pr}(>|z|)$ \\
\hline (Intercept) & 0.3037 & 0.2368 & 1.283 & 0.1997 \\
\hline coda $\$ c l$ assenome & 0.8329 & 0.4592 & 1.814 & 0.0697. \\
\hline coda\$classeverbo & -1.3948 & 0.2666 & -5.232 & $1.68 \mathrm{e}-07 * * *$ \\
\hline coda\$posicaomeio & 1.7758 & 0.4435 & 4.004 & $6.23 e-05 * * *$ \\
\hline
\end{tabular}

Tabela 2: Regressão logística da realização do R em coda silábica (mod1 <-glm(concor\$realizacao concor\$classe + concor $\$$ posicao + concor\$sexo, family $=$ binomial, data $=$ concor $))$

Fonte: Elaborado pela autora com dados da pesquisa.

Esses resultados são semelhantes aos de estudos de fala espontânea, em que há maior ocorrência da supressão de R em coda silábica de verbos no infinitivo (REIS; DIAS, 2006; OUSHIRO; MENDES, 2014) e o não apagamento do R no meio de sílabas (CALLOU et al, 2015). Apesar de Aracaju apresentar o menor percentual de apagamento $(83 \%)$ em relação às demais capitais nordestinas, Callou et al (2015) constatou o a tendência geral ao apagamento do $\mathrm{R}$ em coda final (verbos).

Esses resultados tambék alinham-se aos estudos com dados de leitura em voz alta de Aquino (2011); Hora e Aquino (2012); Araújo et al (2016) e Pinheiro et al (2017), constatado, também, em nossa amostra. Quanto às rotas de leitura, esses resultados sugerem que os leitores assimilaram a variável já consolidada na fala espontânea e nossa hipótese foi confirmada ao constatar que a regra de maior ocorrência, apagamento do $\mathrm{R}$ em coda de verbos no infinito, foi assimilada pelo leitor, assim como a manutenção do $\mathrm{R}$ em sílaba medial. Essa regra variável do vernáculo brasileiro é um traço gradual do fenômeno e não é estigmatizada pela sociedade. Assim, o acesso à rota lexical mostra que a pronúncia é obtida a partir do reconhecimento visual da palavra escrita e que o leitor acessa primeiro o significado antes de pronunciar a palavra que já está armazenada no léxico mental (LUPKER, 2013, p. 62).

\subsection{CONCORDÂNCIA NOMINAL}

A análise da concordância nominal se deu na perspectiva atomística, "em que cada elemento flexionável do SN é uma unidade de análise" (SCHERRE, 1997, p. 184). Assim, foram considerados 1725 elementos nominais extraídos de um total de $10 \mathrm{SN}$, a saber: "todos os dias", "todas as crianças", "os doces", "nos finais", "uns oito anos”, "às vezes", "as crianças", "todos os doces", "todas as vezes", "nessas coisas"; além de outros elementos nominais que estabeleciam relação com antecedentes do texto. 
A
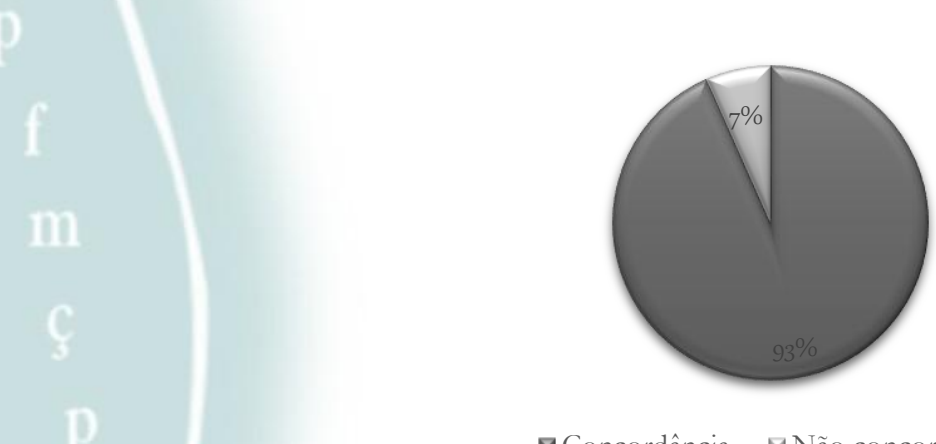

• Concordância $\square$ Não concordância

Gráfico 6: Realização da concordância nominal no corpus.

Fonte: Elaborado pela autora com dados da pesquisa.

No gráfico 6, verificamos que $93 \%$ dos elementos dos $\mathrm{SN}$ receberam a marca de plural, enquanto apenas $7 \%$ não realizaram a concordância nominal de número. Em nossa amostra há $10 \mathrm{SN}$, sendo quatro na configuração [quant.+art.def.+subst.] ("todos os doces”), contexto de maior ocorrência de variantes explícitas de plural (SCHERRE, 1997). Outra variável de alta ocorrência da marca de plural é a saliência do plural irregular ("nos finais"), contexto presente em nosso corpus.

A variável classe gramatical foi analisada para verificar se o fenômeno variável da fala espontânea ocorre da mesma forma na leitura em voz alta (gráfico 7).

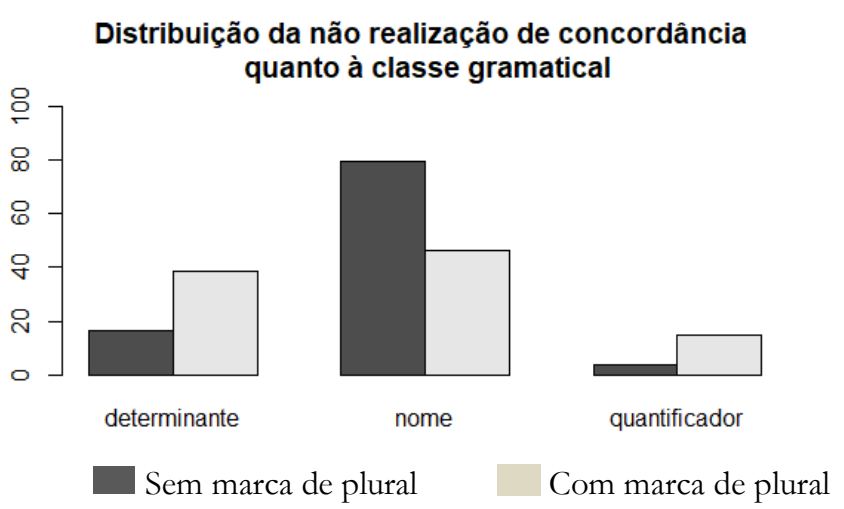

Gráfico 7: Apagamento da marca de plural quanto à classe gramatical.

Fonte: Elaborado pela autora com dados da pesquisa.

Tal resultado mostra que a maior ocorrência de marca zero de plural está no nome e a menor incidência de marca explícita de plural, no quantificador. $\mathrm{O}$ estudo de fala espontânea (SCHERRE, 1997) verificou a relação entre as variáveis posição e classe; em nosso estudo, esta relação pode ser verificada no gráfico 8. 


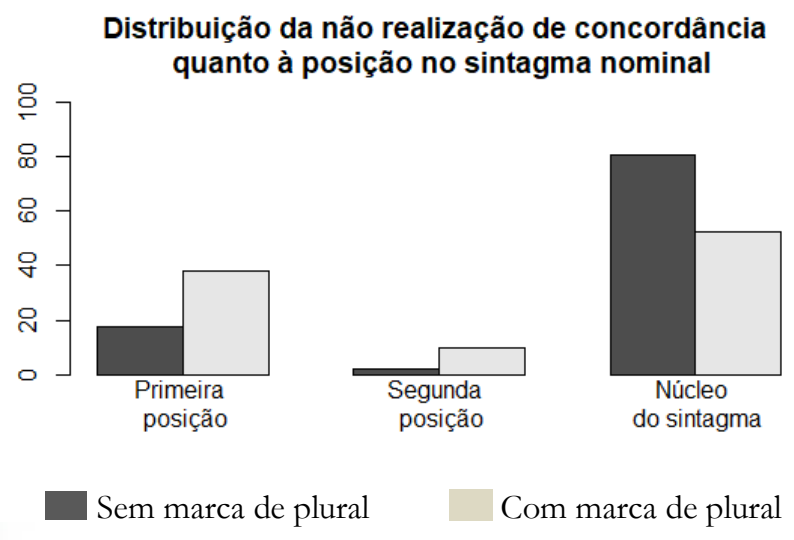

Gráfico 8: Apagamento da marca de plural quanto à posição.

Fonte: Elaborado pela autora com dados da pesquisa.

O gráfico 8 apresenta a realização de marca de plural na concordância nominal quanto à variável posição no SN. Verificamos maior ocorrência de marca zero no núcleo do SN na posição mais à direita. Os estudos de Scherre (1997, p. 185) indicaram que a "classe gramatical e a posição do elemento no SN não têm efeito independente", isto quer dizer que as classes que funcionam como núcleo são relativamente mais sensíveis à posição que ocupam no $\mathrm{SN}$, marcando mais a variante explícita de plural na terceira do que na segunda posição e as classes gramaticais não-nucleares (determinantes), por sua vez, são mais sensíveis à posição da esquerda, apresentando a variante explícita de plural.

Os resultados de maior ocorrência de apagamento da forma de plural no núcleo do sintagma na posição mais à direita podem ser relacionados aos estudos de fala espontânea de Scherre e Naro (1998). Esses resultados também podem ser verificados nos estudos com dados de leitura de Aquino (2011), em que a autora verifica que os leitores passam para a leitura os fenômenos variáveis estigmatizados da fala, principalmente, os leitores mais escolarizados da amostra ( $4^{\circ}$ e $5^{\circ}$ anos).

Verificamos em nossa amostra que a variação na concordância nominal de número do vernáculo brasileiro está internalizada na mente de seus falantes e atende à uma estrutura linguística preestabelecida. Para Scherre e Naro (1998, p. 13),

existe um sistema gerenciando a variação na concordância de número no português do Brasil, sendo, portanto, possível se prever em que estruturas lingüisticas e em que situações sociais os falantes são mais propensos a colocar ou não todas as marcas formais de plural nos elementos flexionáveis das diversas construções.

Essa evidência do fenômeno variável na fala pode ser percebida na leitura em voz alta. Neste sentido, verificamos que o leitor não realizou a concordância nominal de número de elementos do SN na classe nuclear (nome) na posição mais à direita, confirmando a nossa hipótese. Quando o leitor segue essa regra do fenômeno variável da fala demonstra acessar a rota lexical. 
A falta de marca de plural nos elementos do SN é considerada um traço gradual, por ser um fenômeno de variação bastante estruturado na fala espontânea (SCHERRE, 1997), no entanto é estigmatizado socialmente, principalmente nos níveis de maior escolarização e de falantes do sexo feminino (SCHERRE; NARO, 1998, 2006). Como a leitura é um evento de letramento, realizado em uma sala de aula, há maior monitoramento dos leitores e menos ocorrência da falta de concordância nominal de número.

$\mathrm{Na}$ regressão logística quanto à realização de marca de plural nos elementos do SN, chegamos aos resultados da tabela 3.

\begin{tabular}{|c|c|c|c|c|}
\hline (Intercept) & Estimate std. & Error & z value & $\begin{array}{l}\operatorname{Pr}(>|z|)_{* * *} \\
<2 e-16 *{ }^{2}\end{array}$ \\
\hline concor\$classenome & -2.3535 & 1.0146 & -2.320 & $0.020363 *$ \\
\hline concor $\$ c$ lassequantificador & 0.8236 & 0.5630 & 1.463 & 0.143491 \\
\hline concor\$posicao2 & 1.1705 & 0.7561 & 1.548 & 0.121597 \\
\hline concor\$posicaoN & 1.2559 & 1.0327 & 1.216 & 0.223969 \\
\hline concor\$sexomasculino & -0.6857 & 0.2004 & -3.422 & 0.000622 \\
\hline Signif. codes: 0 ' $* * *$ ’ 0. & $* \quad 0.01$ & $\because 0$. & 1 & \\
\hline
\end{tabular}

Tabela 3: Regressão logística da concordância nominal (mod1 <-glm(concor\$realiqacao $\sim$ concor\$classe + concor\$posicao, family = binomial, data $=$ concor $)$ )

Fonte: Elaborado pela autora com dados da pesquisa.

Os resultados apontam para maior tendência da não realização da marca de plural nos nomes e por participantes do sexo masculino. No entanto, não ficou clara a relação entre as variáveis posição e classe gramatical analisadas por Scherre (1997, p. 185), que identificou que há uma relação de dependência na realização da marca de plural entre as classes gramaticais não-nucleares e nucleares em razão da posição no SN.

\section{CONSIDERAÇÕES FINAIS}

Consideramos que os estudos sociolinguísticos para a educação podem contribuir com o ensino-aprendizagem da leitura, no sentido de lidar com a natureza heterogênea da língua e levar em conta os contínuos para a análise da variação linguística (BORTONIRICARDO, 2004).

Retomando os objetivos propostos para este estudo, verificamos que os fenômenos variáveis internalizados na fala do brasileiro são transpostos para a leitura em voz alta dos estudantes informantes deste estudo. Podemos estabelecer relação desse uso com as rotas de leitura, alegando que o uso da rota lexical explica essa transposição, uma vez que o leitor faz uso de seu reportório linguístico para tentar compreender o texto lido, demonstrando ser um leitor proficiente.

Assim, verificar os fenômenos variáveis na leitura em voz alta dos estudantes do $6^{\circ}$ ano do ensino fundamental pode nos dar pistas das rotas de leitura, possibilitando identificar os possíveis leitores proficientes ao contrário de taxar como "erro" o apagamento de $\mathrm{R}$ na desinência verbal de infinitivo ou a realização da concordância nominal somente pelo determinante na posição mais à esquerda ou ainda na monotongação de / ow/ numa avaliação de leitura. 
A verificação de fenômenos variáveis da fala na leitura num ambiente de maior monitoramento nos leva a pensar que esses leitores estão se expressando em linguagem própria para a construção do significado do texto lido, conforme previsto nos PCN (BRASIL, 1998). Essas discussões servem para confirmar a hipótese de que o leitor acessa a rota lexical na leitura em voz alta quando transpõe os traços graduais de maior ocorrência na fala espontânea e menos estigmatizados socialmente.

\section{REFERÊNCIAS}

ARAÚJO, Luna Costa, et al. Processos fonológicos que passam da fala para a leitura: apagamento do / R/ em posição final de palavra na leitura oral. Sociolinguística e Dialetologia: anais eletrônicos Gelne, 2016. p. 291-302.

ÁVILA, Clara Regina Brandão de, et al. Tipologia de erros de leitura de escolares brasileiros considerados bons leitores. Pró-Fono Revista de Atualização Científica, 2009.

BORTONI-RICARDO, Stella Maris. Educaşão em língua materna: a sociolinguística na sala de aula. Parábola, 2004.

BRASIL. Ministério da Educação. Secretaria de Educação Média e Tecnológica. Parâmetros Curriculares Nacionais. Ensino Fundamental: Terceiro e Quartos Ciclos: Língua Portuguesa. Brasília: SEF, 1998.

CALLOU, Dinah; SERRA, Carolina; CUNHA, Claudia. Mudança em curso no português brasileiro: o apagamento do $\mathrm{R}$ no dialeto nordestino. Revista da $A B R A L I N, \mathrm{v} .14, \mathrm{n} .1$, 2015.

CARVALHO, Solange Carlos de. Estudo variável do apagamento dos ditongos decrescentes orais em falantes do Recife. Dissertação de Mestrado. 2007.

CASTANHEIRA, António José Alexandre. Avaliação da fluência da leitura oral em alunos do $5^{\circ}$ ano de escolaridade. Tese de Doutorado. 2011.

CATETE. Grasiele Santos, et al. Processos fonológicos que passam da fala para a leitura: monotongação e ditongação na leitura oral dos alunos do Colégio Estadual Ministro Petrônio Portela, Aracaju/SE. Sociolinguística e Dialetologia: anais eletrônicos Gelne, 2016. p. 303-312.

COLTHEART, Max. Modelando a leitura: a abordagem da dupla rota. In.: SNOWLING, Margaret J.; HULME, Charles (Org.). A Ciência da Leitura. Porto Alegre: Penso, 2013. p. 24-41.

DENO, Stanley L. Developments in curriculum-based measurement. The Journal of Special Education. 37.3. 2003. p. 184-192.

FERREIRA, R. Avaliação da fluência na leitura em crianças com e sem necessidades educativas especiais: validação de uma prova de fluência na leitura para o $2^{\circ}$ ano do $1^{\circ} \mathrm{CEB}$. Dissertação de Mestrado. Universidade Técnica de Lisboa, 2009.

FREITAG, R. M. Ko, et al. Vamos prantar frores no grobo da terra: estudando o rotacismo nas séries iniciais da rede municipal de ensino de Moita Bonita/SE. RevLetRevista Virtual de Letras, v. 2, p. 17-31, 2010. 
FREITAG, Raquel Meister Ko. Banco de dados falares sergipanos. Working Papers em Linguistica, v. 14, n. 2, p. 156-164, 2013.

FREITAG, Raquel Meister Ko. Entre norma e uso, fala e escrita: contribuições da sociolinguística à alfabetização. Nucleus, v. 8, n. 1, 2011.

GORSKI, E. M.; FREITAG, RMK. Ensino de português: demandas teóricas e práticas. In: SILVA, Camilo Rosa (Org.). Lingua materna e ensino: alguns pressupostos para a prática pedagógica. Ideia, João Pessoa, p. 91-125, 2007.

HASBROUCK, Jan; TINDAL, Gerald A. Oral reading fluency norms: A valuable assessment tool for reading teachers. The Reading Teacher. 59.7. 2006. p. 636-644.

HORA, Dermeval da; AQUINO, Maria de Fátima S. Da fala para a leitura: análise variacionista. Alfa: Revista de Linguística, v. 56, n. 3, p. 1099-1115, 2012.

JESUS, Agnaldo Almeida de; SANTOS, Cristiane dos; OLIVEIRA SANTOS, Moniza de. O processo de monotongação na fala dos estudantes universitários-UFS/Itabaiana: uma abordagem sociolinguística. ENILL: anais eletrônicos, v. 01, 2010.

LABERGE, David; SAMUELS, S. Jay. Toward a theory of automatic information processing in reading. Cognitive psychology, v. 6, n. 2, p. 293-323, 1974.

LABOV, William, et al. A graphemic-phonemic analysis of the reading errors of inner city children. Unpublished manuscript. Retrieved June, v. 6, p. 2001, 1998.

LABOV, William; BAKER, Bettina. What is a reading error?. Applied Psycholinguistics, v. 31, n. 4, p. 735-757, 2010 [2003].

LABOV, William; ROBINS, Clarence. A note on the relation of reading failure to peer-group status in urban ghettos. Columbia Univ., New York, 1967.

LUPKER, Stephen J. Reconhecimento visual de palavras: teorias e estudos. In: SNOWLING, Margaret J.; HULME, Charles (Org.). A ciência da leitura. Porto Alegre: Penso Editora, 2013. p. 57-78.

MOLLICA, Maria Cecília de Magalhães; FERNANDEZ, Camille de Miranda. Um caso de estabilidade fonológica comprovado em tempo aparente e em tempo real. Revista de Letras, v. 1, n. 25, 2003.

MORAIS, José. $A$ arte de ler. São Paulo: Ed. da UNESP, 1996.

OUSHIRO, Livia; MENDES, Ronald Beline. O apagamento de (-r) em coda nos limites da variação. Revista Veredas, v. 18, n. 2, 2014.

PINHEIRO, Ângela Maria V.; CUNHA, Carolina Rezende da; LÚCIO, Patrícia Silva. Tarefa de leitura de palavras em voz alta: uma proposta de análise dos erros. Revista Portuguesa de Educação, v. 21, n. 2, p. 115-138, 2008.

PINHEIRO, Bruno Felipe Marques, et al. Processos fonológicos que passam da fala para a leitura. In: AZEVEDO, Isabel Cristina Michelan de, ROIPHE, Alberto (Orgs.). Leitura, escrita e literatura: interseções e convergências. São Cristóvão: Editora UFS, 2017.

RASINSKI, Timothy V. Assessing Reading Fluency. Pacific Resources for Education and Learning (PREL). 2004a.

RASINSKI, Timothy V. Commentary: Speed does matter in reading. The Reading Teacher, 54.2. 2000. p. 146-151. 
RASINSKI, Timothy V., et al. Is reading fluency a key for successful high school reading? Journal of Adolescent \& Adult Literacy, 49.1. 2005. p. 22-27.

RASINSKI, Timothy, et al. The relationship between a silent reading fluency instructional protocol on students' reading comprehension and achievement in an urban school setting. Reading Psychology, 32.1. 2011. p. 75-97.

RASINSKI, Timothy. Creating fluent readers. Educational Leadership, 61.6. 2004b. p. 4651.

REIS, Mariléia; DIAS, Almerinda Bianca Batti. A vibrante final de infinitivo na fala de crianças em fase final de aquisição da linguagem: o efeito cumulativo de natureza fonomorfossintática sobre o fonema /r/. Revista Virtual de Estudos da Linguagem - ReVEL. V. 4, n. 7, agosto de 2006.

SALLES, Jerusa Fumagalli de; PARENTE, Maria Alice de Mattos Pimenta. Avaliação da leitura e escrita de palavras em crianças de $2^{\mathrm{a}}$ série: abordagem neuropsicológica cognitiva. Psicologia: reflexão e crítica. Porto Alegre. Vol. 20, n. 2 (maio/ago. 2007), p. 220 228, 2007.

SALLES, Jerusa Fumagalli de. Habilidades e dificuldades de leitura e escrita em crianças de $2^{a}$ série: abordagem neuropsicológica cognitiva. 2005. Tese de Doutorado. Universidade Federal do Rio Grande do Sul.

SCHERRE, Maria Marta Pereira; NARO, Anthony J. Mudança sem mudança: a concordância de número no português brasileiro. Scripta, v. 10, n. 18, p. 107-129, 2006.

SCHERRE, Maria Marta Pereira; NARO, Anthony Julius. Sobre a concordância de número no português falado do Brasil. Dialettologia, geolinguistica, sociolinguistica, p. 509-523, 1998.

SCHERRE, Maria Marta Pereira. Concordância nominal e funcionalismo. ALFA: Revista de Linguística, v. 41, n. 1, 1997.

TRISTÃO, Flora Saudan Correia. Avaliação da fluência de leitura oral em alunos de $2^{\circ}$ ano do $1^{\circ}$ ciclo. 2009. Tese de Doutorado. 